\title{
The structure and protein binding of amyloid-specific dye reagents ${ }^{\star \star}$
}

\author{
Barbara Stopa $^{1 凶}$, Barbara Piekarska ${ }^{1}$, Leszek Konieczny ${ }^{1}$, Janina Rybarska ${ }^{1}$, \\ Paweł Spólnik ${ }^{1}$, Grzegorz Zemanek ${ }^{1}$, Irena Roterman ${ }^{2}$ and Marcin Król ${ }^{2}$ \\ ${ }^{1}$ Institute of Medical Biochemistry, and ${ }^{2}$ Department of Bioinformatics and Telemedicine, \\ Collegium Medicum, Jagiellonian University, Kraków, Poland
}

Received: 12 May, 2003; revised: 28 August, 2003; accepted: 15 September, 2003

Key words: Congo red, amyloid, supramolecularity, dye-protein complexation, immunoglobulin light chain

\begin{abstract}
The self-assembling tendency and protein complexation capability of dyes related to Congo red and also some dyes of different structure were compared to explain the mechanism of Congo red binding and the reason for its specific affinity for $\beta$-structure. Complexation with proteins was measured directly and expressed as the number of dye molecules bound to heat-aggregated IgG and to two light chains with different structural stability. Binding of dyes to rabbit antibodies was measured indirectly as the enhancement effect of the dye on immune complex formation. Self-assembling was tested using dynamic light scattering to measure the size of the supramolecular assemblies. In general the results show that the supramolecular form of a dye is the main factor determining its complexation capability. Dyes that in their compact supramolecular organization are ribbon-shaped may adhere to polypeptides of $\beta$-conformation due to the architectural compatibility in this unique structural form. The optimal fit in complexation seems to depend on two contradictory factors involving, on the one hand, the compactness of the non-covalently stabilized supramolecular ligand, and the dynamic character producing its plasticity on the other. As a result, the highest protein binding capability is shown by dyes with a moderate self-assembling tendency, while those arranging into either very rigid or very unstable supramolecular entities are less able to bind.
\end{abstract}

\footnotetext{
${ }^{\star}$ Report on the same subject was presented at the Fifth European Symposium of The Protein Society, 2003, Florence, Italy.

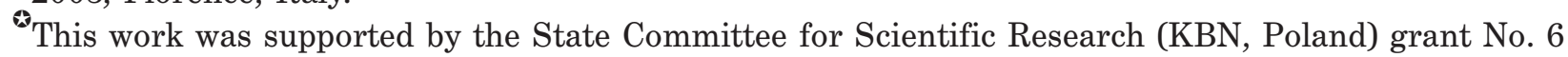
P05F 01220.

${ }^{\bowtie}$ Barbara Stopa, Institute of Medical Biochemistry, Collegium Medicum, Jagiellonian University, M. Kopernika 7, 31-034 Kraków, Poland; tel/fax: (48 12) 422 3272; e-mail: mbstopa@cyf-kr.edu.pl Abbreviations: R, hydrodynamic radius of dye supramolecular assembly; SRBC, sheep red blood cells.
} 
The dye Congo red, which for years was regarded as an amyloid-specific stain, recently was found to form complexes with some other proteins (Rybarska et al.,1988; Piekarska et al., 1996; Roterman et al., 1998; Khurana et al., 2001; Zemanek et al., 2002). Global or local structural instability seems to characterize all the proteins that bind the dye (Wetzel, 1997; Wall et al., 1999; Raffen et al., 1999; Ramirez-Alvarado et al., 2000; Kim et al., 2000; Randolph et al., 2002). Another common feature correlated with dye binding is accessibility of $\beta$-conformation polypeptide chain backbones (Glenner et al., 1972; 1974; Serpel et al., 1997; Sunde \& Blake, 1998; Kallberg et al., 2001). Many approaches have been employed to identify the mechanism of complexation and the structure of the protein sites responsible for specific dye attachment (Westermark et al., 1999; Demaimay et al., 1998; Li et al., 1999; Gazit, 2002). Surprisingly, many dyes not necessarily similar to Congo red appear to bind to amyloid proteins (Klunk et al., 1994; Pollack et al., 1995; Caughey et al., 1998; Carter \& Chou 1998; Howlett et al., 1999a; 1999b; Priola et al., 1999; Kuner et al., 2000; Reixach et al., 2000; Rudyk et al., 2000; Awan et al., 2001; Lin et al., 2001), and many quite different proteins may form amyloid deposits that create binding sites specific for Congo red (Sipe, 1992; Sunde \& Blacke, 1997; Chiti et al., 1999; Lansbury, 1999; Janek et al., 1999; Rostagno et al., 1999; West et al., 1999; Sinha et al., 2001). This suggests that the standard enzyme-substrate model of ligand complexation to a specific binding site may not apply in this case.

We put forward an alternative proposal to explain these discrepancies, arguing that Congo red binds to proteins not as a single molecule but as a ligand represented by a group of self-assembled dye molecules (Roterman et al., 1993; Skowronek et al., 1998; Piekarska et al., 1999; Roterman et al., 2001). The polyaromatic ring character of these dyes, correlated with the elongated shape, planarity and significant hydrophobicity of the molecules, favors self-assembling by face-to-face ring stacking (Wasilewskaya et al., 1989; Attwood et al., 1990; Skowronek et al., 2000; Piekarska et al., 2001). This results in the creation of unique ribbon-like micellar species capable of interacting with a protein - not by entering its natural binding site but by adhesion to the backbone of $\beta$-conformation polypeptide chains, due to the structural similarity of the interacting elements (Roterman et al., 1993; Piekarska et al., 1999; Roterman et al., 2001). The large interaction surface of the ribbon-shaped dye micelle, its plasticity, and in particular the exposure of the hydrophobic portions of the dye molecules to solvent which in micellar organizations is exceptional - favor adhesion to periodic polymers including polypeptide chains, and thus the formation of highly stable complexes. In such a complexation mechanism several assembled dye molecules interact with the protein as a single ligand (Roterman et al., 1998; Piekarska et al., 1999; Roterman et al., 2001). The model only works if the dye-dye interaction is strong enough to make the assembly compact and if this large supramolecular ligand can penetrate the $\beta$-pleated sheet easily. Protein instability seems necessary for the penetration to occur. However, antibodies and serpins may bind the dye when altered upon complexation with their natural ligands (Piekarska et al., 1994; Rybarska et al., 1995).

The diversity of the supramolecular forms of dyes results from differences in the structures of the monomers, and consequently different arrangements of their self-assembled molecules, making their protein complexation capability vary. This work compares the structures, self-assembling and protein binding activity of many dyes related and not related to Congo red, to verify the hypothesis that their binding specificity derives from their supramolecular character. We measured the protein-binding capability of the dyes using unstable proteins of immunoglob- 
ulin origin often found as sources of amyloid deposits and hence expected to represent complexation characteristics similar to that of amyloid.

\section{MATERIALS AND METHODS}

Dyes. Some dyes of the Congo red family [2,7-bis(1-amino-4-sulfonaphthyl-2-azo)fluorene, 1,4-bis(1-amino-4-sulfonaphthyl-2-azo)phenylene, 1-amino-2-[4'-(4-acetylamino-biphenyl)azo]naphthalene-4-sulfonic acid, 1-amino2-phenylazo-naphthalene-4-sulfonic acid] were synthesized, according to described methods (Neri, 1929; Rollet \& Bacher, 1940; Novelli \& Ruiz, 1928; Stopa et al., 1998). The dyes: 2-formylamino-4,4'-bis(1-amino-4-sulfonaphthyl-2-azo)biphenyl, 2-acetylamino-4,4' bis(1-amino-4-sulfonaphthyl-2-azo)biphenyl and 2-benzoylamino-4,4'-bis(1-amino-4-sulfonaphthyl-2-azo)biphenyl were synthesized from 2-amino-4,4'-dinitrobiphenyl (Zhen et al., 1999). Suitable acid chlorides were then added to make the final products. Chrysamine $\mathrm{G}$ and 4,4'-bis(1-amino-5-sulfonaphthyl-2-azo)biphenyl were synthesized by diazotization of benzidine and coupling with salicylic acid and 1-amino-naphthalene-5-sulfonic acid, respectively. Other dyes were purchased from Sigma-Aldrich.

Dye purity. Quantitative evaluation of self-assembling dyes poses particular difficulties (Lyon, 2002). Readily self-assembling dyes may incorporate derivatives produced during synthesis, very difficult to remove because of their structural similarity to the main fraction. In addition, these dyes are basically unattainable in crystal forms; they are often associated with impurities, moreover, self-assembling usually produces some heterogeneity.

We did preliminary testing of the protein-binding properties of the dyes. Dyes that showed very low protein-binding capability and migrated (in thin-layer silica gel chromatography) as a single band or were associated with small amounts of color impurities were used directly without further purification. In these cases the absorption coefficients were calculated from weights, taking into account the producer's declaration on dye purity. Dyes with significant impurity content were purified for analysis by chromatography using preparative thin-layer silica gel plates (Merck silica gel 60). Dyes of higher reactivity, mostly of the Congo red and Evans blue families were purified by preparative thin-layer chromatography if necessary. The absorption coefficients used for Evans blue, Trypan blue and Chicago Sky blue 6B were taken from the producer's website (Sigma) and independently verified experimentally. The absorption coefficients of the Congo red family (all dyes containing naphthionic acid) were established based on the fluorescence of naphthionic acid derivatives (1,2-diamino-naphthalene-4-sulfonic acid) released from the dye by reduction of its azo bonds with sodium dithionite. The corresponding Congo red fluorescent derivatives were used to standardize the method.

Dye structure. Formulas of the dyes were drawn using the ISIS Draw 2.4 program. Three-dimensional forms of dye structure were obtained using HyperChem ver. 5 with the energy optimization procedures available in this program.

Evaluation of self-assembling by measurement of the hydrodynamic radius. The hydrodynamic radii (R) of dye supramolecular assemblies were measured using Dynamic Light Scattering (DLS) with a DynaPro MS 800 instrument (Protein Solutions Inc., U.S.A.). Measurements were performed at $25^{\circ} \mathrm{C}$ in $0.06 \mathrm{M}$ barbitate buffer, $\mathrm{pH}$ 8.6, $0.1 \mathrm{M}$ $\mathrm{NaCl}$, at $2 \mathrm{mM}$ dye concentration. When the presence of polymeric impurities was suspected, $\mathrm{R}$ was also measured at $60^{\circ} \mathrm{C}$ to identify the non-covalently stabilized dye species by the significant alteration of their size (R).

Prior to measurements the dye solutions were heated in a boiling bath and then slowly cooled to room temperature. Each dye mea- 
surement was repeated several times and the mean values were calculated. The main component appearing in DLS analysis was considered to represent the micellar species typical for the given dye.

Proteins. Immunoglobulin G was purchased from Sandoz Pharma Ltd. (Switzerland). Immunoglobulin light chain dimers $\mathrm{L}_{\mathrm{An}}$ and $\mathrm{L}_{\mathrm{Kok}}$ were isolated from the urine of patients with multiple myeloma as described earlier (Piekarska et al., 1996).

Dye-protein complexation The protein complexation capability of a dye was evaluated by measuring the number of dye molecules bound to a protein molecule. Dye and protein solutions were mixed in a ratio of 0.6 $\mu \mathrm{mol}$ dye per $1 \mathrm{mg}$ protein (in $0.06 \mathrm{M}$ barbitate buffer, $\mathrm{pH}$ 8.6, $0.1 \mathrm{M} \mathrm{NaCl}$ ). A large dye excess was used for complexation to minimize the effect of possible impurities. Samples were incubated for $20 \mathrm{~min}$ at $20^{\circ} \mathrm{C}$ for $\mathrm{L}_{\mathrm{Kok}}$, at $45^{\circ} \mathrm{C}$ for $\mathrm{L}_{\mathrm{An}}$ and $63^{\circ} \mathrm{C}$ for IgG. After incubation the dye-protein complexes were separated from the dye excess by gel filtration on Biogel P6 (Biorad) columns $(4.5 \times 0.5 \mathrm{~cm})$ in the same buffer. The dye/protein ratio in the eluates was calculated based on the known amount of protein applied to the column and on spectral measurement of the dye concentration.

Differences in the adsorption of the dyes to the Biogel influenced the results and necessitated correction. Biogel filtration removes the dye excess and some of the weakly bound supramolecular dye attached to the protein but not anchored deeply. The specific adsorption of the dyes (assessed in an independent experiment) was equalized to minimize the artifact in comparing the dye/protein binding: the number of dye molecules bound was corrected to the deviation of its specific adsorption from the mean adsorption calculated for all studied dyes. This was done using the specific coefficient of adsorption to Biogel estimated for each individual dye. In consequence, the number of dye molecules added for correction of the experimentally deter- mined value was found by multiplying the number of dye molecules bound to protein by the coefficient, calculated as the ratio of deviation of adsorption of a given dye to Biogel from the mean value (mean specific adsorption of all studied dyes) to the mean adsorption value.

Agglutination enhancement. The increased stability of the immune complex caused by the dye increases the antibody dilution at which red cells (SRBC, sheep red blood cells) still agglutinate with IgG anti-SRBC. The effect of the dyes on agglutination was studied at increasing dye concentrations. Enhancement is measured as the maximum dilution of antibodies at which agglutination is observed in the presence of a given dye, at the dye concentration at which the plateau of enhancement is reached (Stopa et al., 1998). The effect observed in the presence of Congo red was used as an internal reference for all other dyes.

\section{RESULTS}

The yield of protein-dye complexation was compared in four dye-binding proteins of different packing stability and hence different accessibility for dyes. All were of immunoglobulin origin, having similar folds with $\beta$-conformation predominant.

Heat-aggregated human IgG was used as the model protein form with the most unstable structure and the lowest structural specificity requirement for the ligand. Two human immunoglobulin $\mathrm{L}$ chains $\lambda$ (Kok and An) obtained from the urine of myeloma patients represented protein molecules having stability lower than that of a well-packed protein but higher than its molten globule version. The first (L chain Kok) was an amyloidogenic protein binding Congo red at room temperature but still unable to bind ANS (1-anilino-8-naphtalenesulfonate) - in contrast to heat-aggregated IgG (Piekarska et al., 1996). The second one (L chain An) was 
non-amyloidogenic $\lambda$ chain able to bind Congo red upon moderate heating to $40-45^{\circ} \mathrm{C}$ (Piekarska et al., 2001). The binding capability of these three proteins was evaluated directly by measuring the amount of dye attached. The number of dye molecules bound to a protein was measured after the complexes were separated by filtration on a Biogel P6 column or by agarose gel electrophoresis, in the same conditions for all studied dyes. The fourth protein system used was represented by rabbit antibodies specific to sheep red cells. In this case, dye binding was measured indirectly by the enhancement of agglutination in the SRBC-antiSRBC system, caused by ligation of the dye to the antibodies interacting with the antigen (Rybarska et al., 1991; Stopa et al., 1998).

Congo red and some related dyes have been found to strengthen immune complexes through the involvement of low-affinity antibodies that become transiently susceptible to dye complexation during their brief contact with the antigen (Rybarska et al., 1991). At increasing dye concentrations the enhancement effect increases until it reaches a plateau indicating that the dye cannot further engage the weak antibodies to the immune complex. Thus, the enhancement is measured as the maximum possible dilution of anti-SRBC antibodies at which agglutination occurs. This value, labeled D in this work, differs for different dyes.

We assumed that in the case of ribbon- or rod-like micellar products of self-association the self-assembling tendency of the dyes may be expressed by the diffusion coefficient or by the size of the supramolecular species. The measurement used dynamic light scattering to determine the hydrodynamic radius of the micellar species, called $R$ here.

Some of the dyes selected for this study were basically related to the molecular architecture of Congo red. They were represented by elongated, symmetric polyaromatic ring molecules of planar structure, with a hydrophobic central fragment and charged ends.
Each dye differed from Congo red in its charge distribution, steric effects, planarity and/or symmetry. We used some dyes unlike Congo red in molecular structure to verify the hypothesis of supramolecular dye ligand interaction with protein. The dyes with similar structural features are presented in groups to highlight the effects of structural differences (Figs. $1 \mathrm{a}-\mathrm{i}$ ). The adjoined comments direct attention to the dyes' particular structural features and properties that may affect their self-assembling and/or complexation capability.

The results are summarized in plots of binding properties versus $\mathrm{R}$ (Figs. 2, 3). They show that supramolecular organization seems necessary for protein binding and that the optimum $R$ value is in the range of $1.3-2.2 \mathrm{~nm}$. Protein complexation of dyes that show a very high self-assembling tendency is not favored. However, deviations from predicted behavior may be expected if the size of the monomers is larger than the size of dyes of the Congo red family and/or if the dye creates a different micellar organization, thus affecting the reading of $\mathrm{R}$, as is likely in the case of thioflavin S. Also, dyes not assembled or poorly assembled fail to form complexes with the proteins used. The spectrum of protein-binding activity versus self-assembling tendency differs, however, when complexation to proteins and enhancement of agglutination are compared (Fig. 2). More flexible supramolecular dye ligands seem preferable for the enhancement of agglutination. This explains why fluorene analog of Congo red (dye No. 3), which shows the highest protein complexation activity in respect to $\mathrm{L}$ chains and heat-aggregated IgG amongst the studied dyes, loses in the agglutination enhancement test to Congo red and Evans blue, dyes of higher plasticity which offer rapid fitting to the sites of their binding in the protein.

Binding or non-binding of a dye was independently verified by analyzing migration of the protein-dye complex in agarose electrophoresis (Fig. 4). The number of dye mole- 


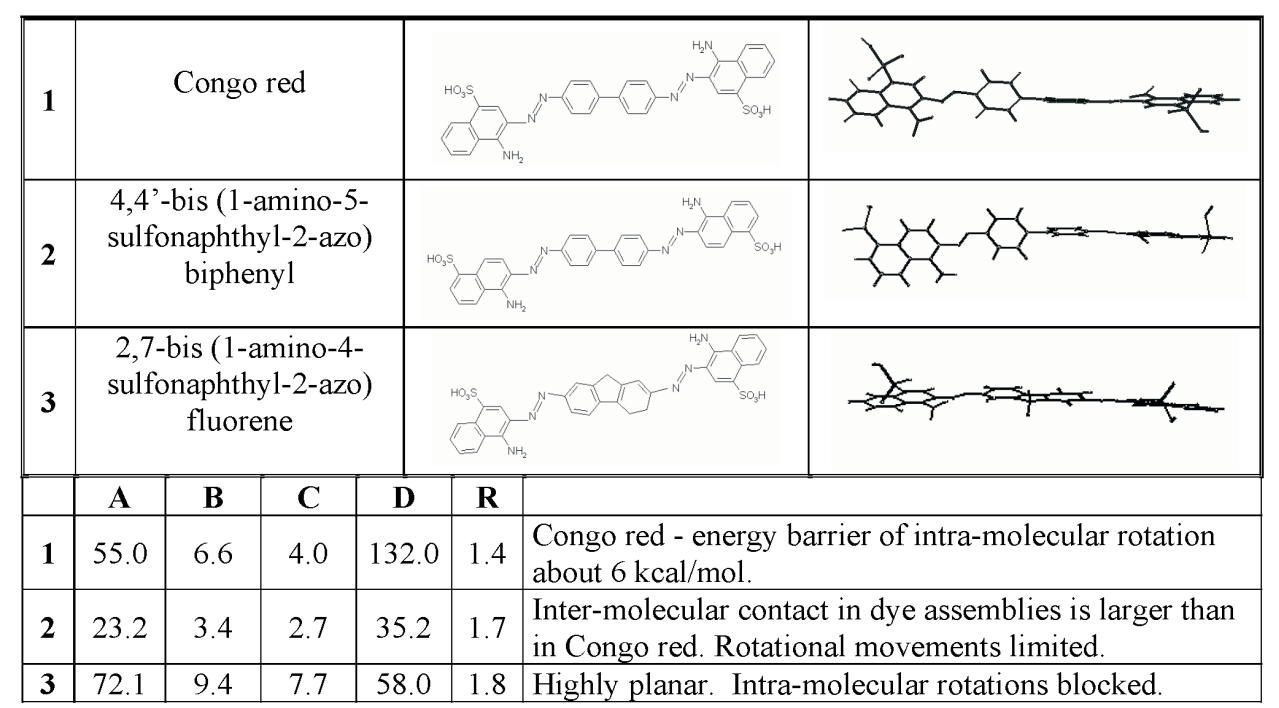

Figure. 1 a. Effect of intra- and inter-molecular rotational freedom of the dye molecule on self-assembling and protein complexation.

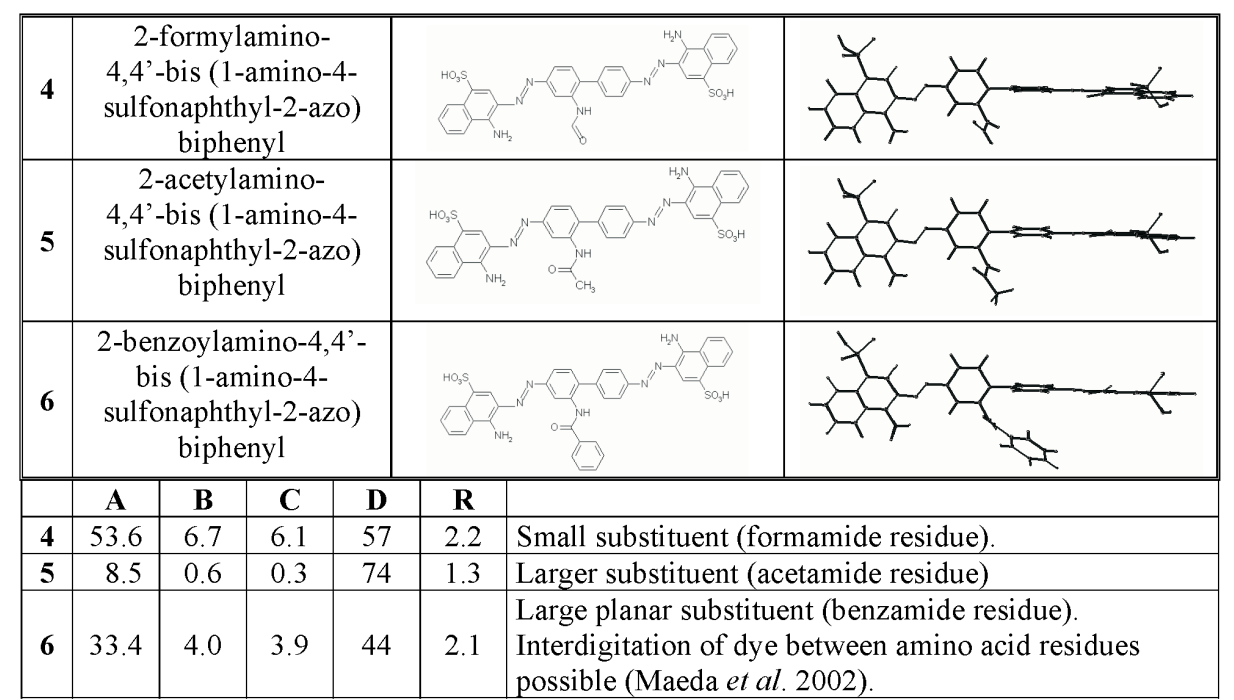

Figure 1 b. Congo red properties altered by substituting residues of different sizes and shapes to the biphenyl fragment.

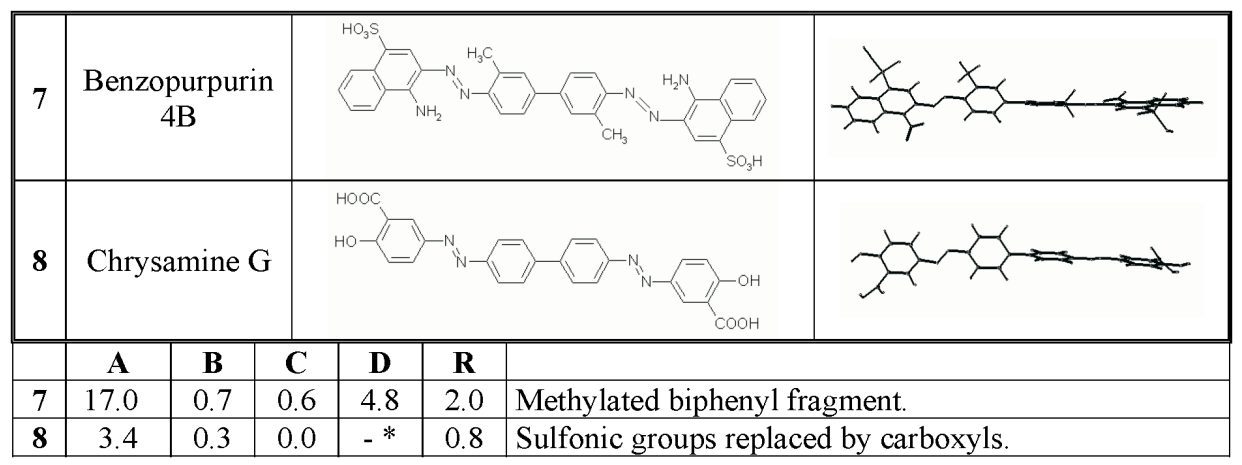

Figure 1 c. Effect of low dye polarity and solubility.

Expected clustering of individual micellar entities. Low solubility in the conditions used makes comparison with other dyes difficult. *Not determined due to very low solubility. 


\begin{tabular}{|c|c|c|c|c|c|c|c|}
\hline 9 & \multicolumn{4}{|c|}{$\begin{array}{l}\text { 1,4-bis (1-amino-4- } \\
\text { sulphonaphthyl-2-azo) } \\
\text { phenylene }\end{array}$} & & & ट्रद \\
\hline 10 & \multicolumn{4}{|c|}{ Acid red 73} & & & \\
\hline 11 & \multicolumn{4}{|c|}{$\begin{array}{l}\text { 1-amino-2-[4'-(4- } \\
\text { acetytaminobiphenyl) } \\
\text { azo]-naphthalene- } \\
\text { 4-sulfonic acid } \\
\end{array}$} & & \\
\hline & $\mathbf{A}$ & B & $\overline{\mathrm{C}}$ & D & $\mathbf{R}$ & & \\
\hline 9 & 2.2 & 0.1 & 0.0 & 0.0 & 1.0 & \multicolumn{2}{|c|}{$\begin{array}{l}\text { Biphenyl reduced to single aromatic ring. Lack of } \\
\text { elongated central hydrophobic fragment. No imposed } \\
\text { orientation of self-assembling molecules. }\end{array}$} \\
\hline 10 & 0.5 & 0.0 & 0.0 & 19.3 & 4.5 & \multicolumn{2}{|c|}{$\begin{array}{l}\text { Highly planar, constant ring spacing favors self- } \\
\text { assembling mediated by symmetric dimeric units with } \\
\text { architecture similar to dye } 9\left(C_{2} \text { or } C_{n} \text { symmetry }\right. \\
\text { possible alternatively }) \text {. }\end{array}$} \\
\hline 11 & 14.8 & 1.0 & 0.5 & 84.0 & 2.1 & \multicolumn{2}{|c|}{$\begin{array}{l}\text { Preserved standard biphenyl fragment and different } \\
\text { ring spacing likely impose a self-assembling } \\
\text { arrangement as with Congo red, in contrast to the } \\
\text { apparently similar dye } 10 .\end{array}$} \\
\hline
\end{tabular}

Figure $1 \mathrm{~d}$. Role of the hydrophobic biphenyl fragment and/or charged naphthyl rings (imposing the parallel orientation of self-assembling molecules) in the formation of suitable for protein complexation supramolecular dye ligands.

\begin{tabular}{|c|c|c|c|c|c|c|c|}
\hline 12 & \multicolumn{3}{|c|}{ Evans blue } & & & & $t+5-5-5$ \\
\hline 13 & \multicolumn{3}{|c|}{$\begin{array}{c}\text { Chicago sky blue } \\
6 \mathrm{~B}\end{array}$} & & & & \\
\hline \multirow[t]{2}{*}{14} & \multicolumn{3}{|c|}{ Trypan blue } & \multirow{3}{*}{\multicolumn{2}{|c|}{\begin{tabular}{|c|c|}
$\mathbf{D}$ & $\mathbf{R}$ \\
\end{tabular}}} & & \\
\hline & $\mathbf{A}$ & B & $\mathrm{C}$ & & & & \\
\hline 12 & 24.3 & 2.3 & 1.6 & & 1.5 & \multicolumn{2}{|c|}{ Supramolecular assemblies of moderate stability. } \\
\hline 13 & 23.3 & 2.3 & 1.8 & 21 & 1.3 & \multicolumn{2}{|c|}{ Steric hindrance effect in complexation possible. } \\
\hline 14 & 5.5 & 0.7 & 0.2 & 2.7 & 0.8 & \multicolumn{2}{|c|}{$\begin{array}{l}\text { Evans blue isomer. Location of sulfonic group close to } \\
\text { azo bonds and biphenyl fragment disturbs self- } \\
\text { assembling and complexation (Skowronek et al. 2000). }\end{array}$} \\
\hline
\end{tabular}

Figure 1 e. Evans blue family. Self-assembling balanced by increased (versus Congo red) hydrophobicity (methylated biphenyl) and charge repulsion (four sulfonic groups).

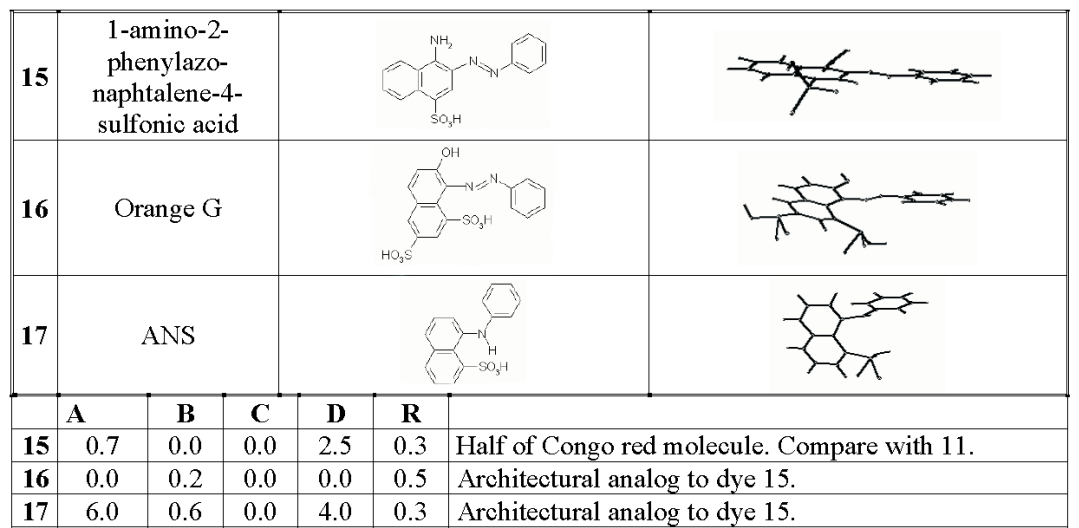

Figure $1 \mathrm{f}$. Molecules having general architecture corresponding to symmetric halves of Congo red. Loss of Congo red-type self-assembling attributes.

ANS, 1-anilino-8-naphtalenesulfonate. 


\begin{tabular}{|l|c|c|c|c|c|c|c|}
\hline 18 & Direct red 80 & \multicolumn{3}{|c|}{} \\
\hline $\mathbf{1 9}$ & Chrysophenine & Direct yellow 9 & & $\mathbf{R}$ & \\
\hline $\mathbf{1 8}$ & 2.2 & 0.4 & 0.0 & 11.2 & 2.3 & $\begin{array}{l}\text { Planar, very large molecule. Steric and charge } \\
\text { difficulties probable in formation of complexes with } \\
\text { proteins. }\end{array}$ \\
\hline $\mathbf{1 9}$ & 8.7 & 0.3 & 0.0 & 3.9 & 0.5 & $\begin{array}{l}\text { Central location of polar groups unsuitable for } \\
\text { complexation with proteins. Arrangement of } \\
\text { molecules in self-assembling unlike Congo red. }\end{array}$ \\
\hline $\mathbf{2 0}$ & 13.7 & 1.2 & 0.0 & 2.0 & 2.8 & $\begin{array}{l}\text { Planarity disturbed by the central bond. } \\
\text { Supramolecular structure likely different from that of } \\
\text { Congo red. }\end{array}$ \\
\hline
\end{tabular}

Figure 1 g. Symmetric, rigid, elongated molecules. Self-assembling and/or protein complexation disturbed by improper charge distribution or steric hindrance.

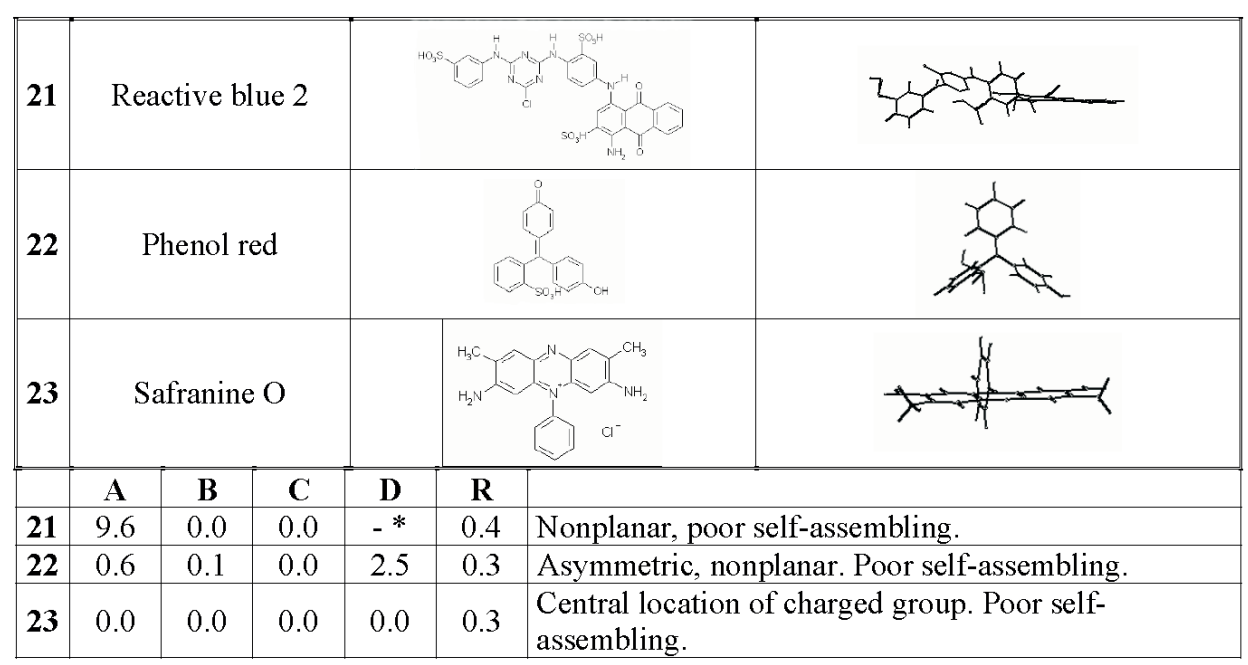

Figure 1 h. Dyes having molecular architecture unrelated to Congo red.

*Not determined because of technical problems.

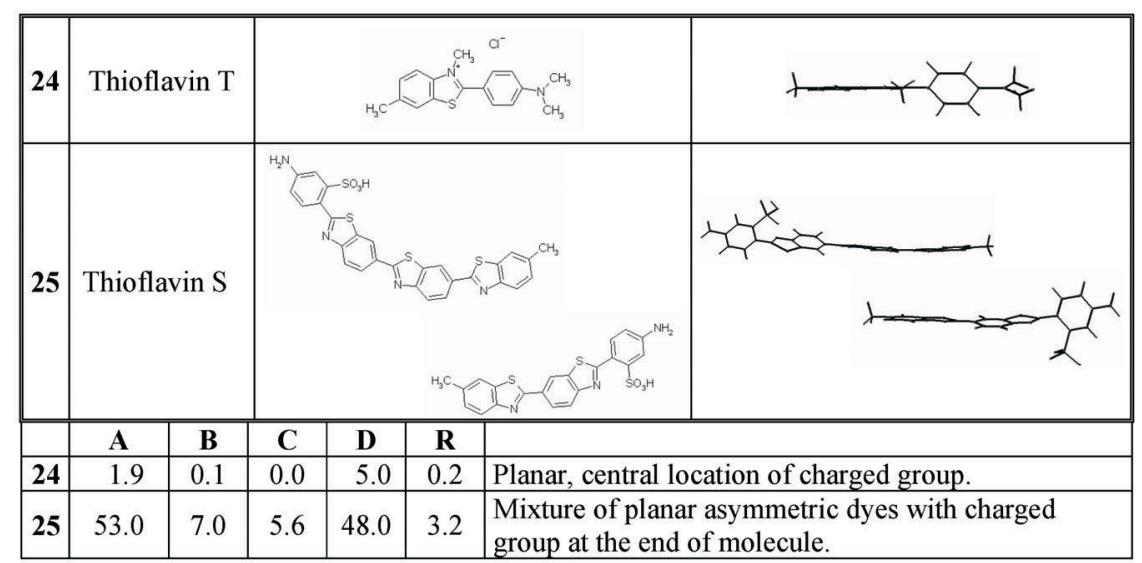

Figure 1 i. Thioflavins - dyes used interchangeably with Congo red to stain amyloids. 

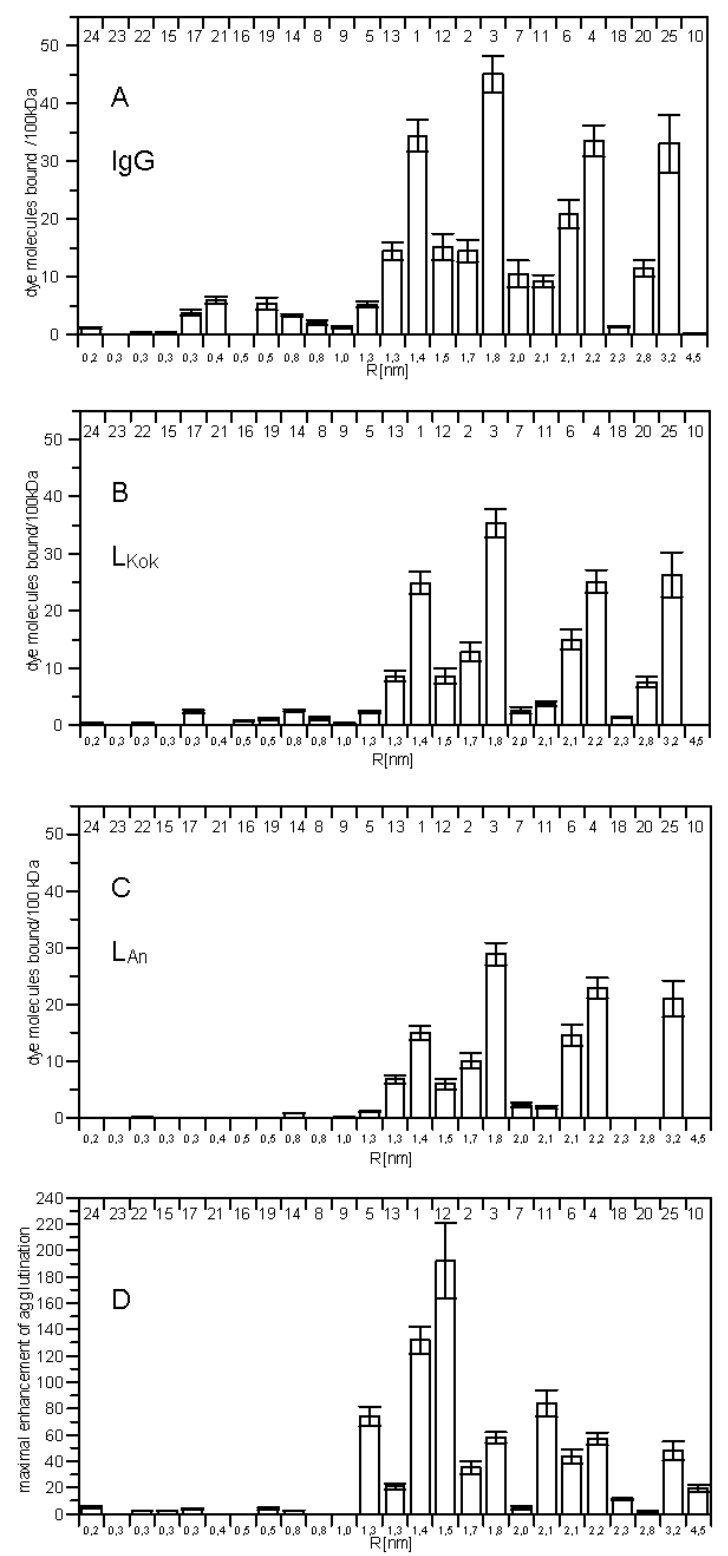

Figure 2. Comparison of protein complexation capabilities of dyes, in order of increasing self-assembling tendency.

$\mathrm{R}$, hydrodynamic radius of the main supramolecular form. Numbers at the top of each graph correspond to dye numbers in Fig. 1. Panels A, B and C, the number of dye molecules bound to each protein after gel filtration was recalculated for $100 \mathrm{kDa}$. Panel $\mathrm{D}$, the enhancement effect of dyes on immune complex stability, evaluated in SRBC-antiSRBC system.

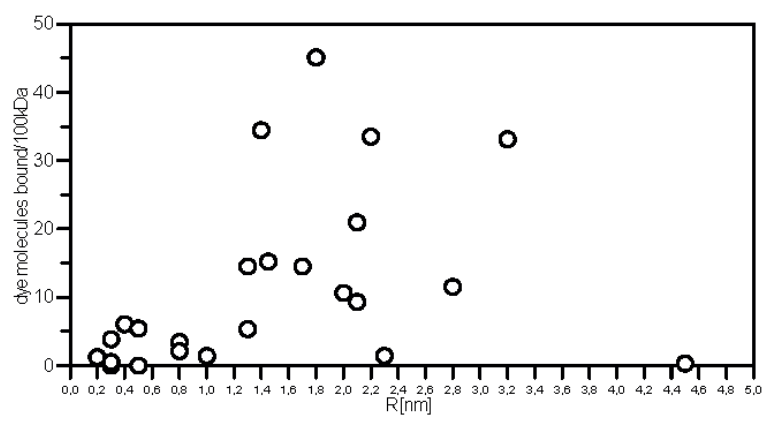

Figure 3. Correlation between hydrodynamic radius (R) of dye self-assemblies and their ability to form complexes with heat-aggregated IgG.

cules bound to protein observed in this testing system is basically higher than in the chromatographic technique because the bed absorbs only weakly (not shown). Reading precision is poor in this test, and it is difficult to use for quantitative analysis, but the method was performed to support the observations of the dye-binding capability revealed by the gel filtration tests.

\section{DISCUSSION}

The evidence supplied by our studies supports the hypothesis of Congo red's specific binding capability arising from the particular supramolecular form of this dye (Skowronek et al., 1998; Piekarska et al., 1999; Roterman et al., 2001, Rybarska et al., 2001). It explains the binding specificity by the adhesion of ribbon-like supramolecular dye species to $\beta$-conformation polypeptides.

Two somewhat contradictory factors seem to determine the particular dye binding mechanism that finally ensures the best possible fit and adhesion of the supramolecular dye ligands within the protein: (1) the strength of

Figure 1 (a-i). Relation of molecular architecture to self-assembling and protein-complexation capability in groups of dyes.

Symbols used: A, number of dye molecules bound to heat-aggregated IgG (160 kDa); B, number of dye molecules bound to monomer of $\mathrm{L}$ chain $\lambda \operatorname{Kok}\left(23.5 \mathrm{kDa}, 20^{\circ} \mathrm{C}\right)$; $\mathbf{C}$, number of dye molecules bound to $\mathrm{L}$ chain $\lambda \mathrm{An}(23.5 \mathrm{kDa}$, $45^{\circ} \mathrm{C}$ ); D, enhancement of agglutination caused by dyes (SRBC-anti-SRBC system); $\mathbf{R}$, hydrodynamic radius of predominant micellar species $(\mathrm{nm})$. 


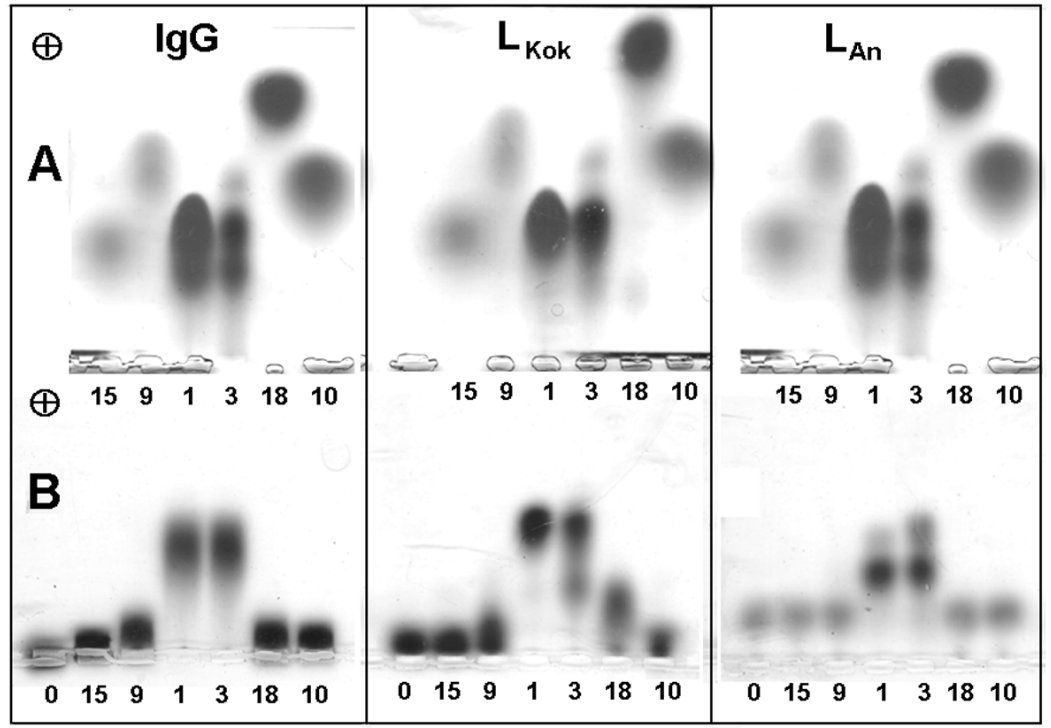

Figure 4. Protein-binding ability of selected dyes studied by agarose gel electrophoresis (pH 8.6). Numbers below each lane correspond to those used in Fig. 1.

0, control sample (no dye). A, gel before staining for protein; B, after staining with bromophenol blue and removal of dyes by reduction with sodium dithionite.

self-association increasing the stability of the dye assemblies, sufficient to make them interact with polypeptides as compact ligands; and (2) their plasticity, which arises from the dynamic micellar form of the dye and facilitates optimal fitting within the complex. The movements of individual dye molecules allowed in the supramolecular ligand, which are necessary for micellar plasticity, involve rotations around the long axis of the ribbon-like micelle as well as around the long axis of the particular molecule. The latter consists in rotations around the central bond of a symmetric dye molecule, producing syn and anti conformers (Skowronek et al., 2000). The compactness of the micellar structures increases with the planarity of the dye molecule, its hydrophobicity, and enlargement of the stacking area. Increasing charge repulsion and/or steric hindrance reduce micellar rigidity, associated in consequence with higher freedom of molecular movements. These contradictory effects determining protein complexation make the binding capability optimal not at a very high but rather at an intermediate level of the dye's self-assembling. The central hydrophobic parts of the dye molecules seem to be preferentially engaged in interaction with the polypeptide backbone (Demaimay et al., 1998). The role of the charged parts of the molecule, and in particular of the charge distribution, does not seem negligible, however. Only symmetric, rigid, planar, polyaromatic dye molecules with charged groups located at the ends, with the necessary elongated, hydrophobic central fragment (biphenyl), may impose the orientation of stacked molecules that ensures the formation of ribbon-shaped supramolecular structures (Wasilewskaya et al., 1989; Attwood et al., 1990; Piekarska et al., 1999).

Among the many different supramolecular assemblies, ribbon-shaped micellar species seem to expose the hydrophobic surface most efficiently, favoring adhesion. The polypeptide backbone likely represents the corresponding structure for adhesion. Although both adhering elements - the dye and polypeptide - are similar in their chain-like character, fitting optimization seems necessary for complex formation since their chemical nature is significantly different. This takes time, particularly when the interacting structures are rigid. This explains why dyes of high micellar rigidity that complex efficiently when incubated with proteins of un- 
stable structure appear less suitable for ligation to low-affinity antibodies (largely represented in the polyvalent IgG fraction); those antibodies offer only brief contact with the antigen and consequently brief or too brief protein accessibility to allow for optimization of the dye-protein adhesion structure and complexation (Rybarska et al., 1991; Kaszuba et al., 1993; Stopa et al., 1998).

Although growing evidence links Congo red's specific binding property with its supramolecularity and implicates $\beta$-conformation polypeptides as the receptor structure in the protein, other ligation mechanisms may also be engaged in particular situations. Thus, a single Congo red molecule bound to a specific site in the protein was found in pig insulin crystals (Turnell \& Finch, 1992). Other studies have supplied evidence of Congo red-bridging protein molecules (Khurana et al., 2001). However, the hypothesis that the binding of Congo red-related dyes is associated with their supramolecular character seems to offer a general explanation of their specific affinity to $\beta$-structure (Piekarska et al., 1996; 2001; Roterman et al., 2001). Although supramolecularity seems the most essential factor in the binding capability of the group of studied dyes, a direct relation to the $R$ value cannot be expected due to the shapeand charge-derived polymorphism of supramolecular ligands.

While the specific affinity of Congo red to amyloid deposits can be explained by the particular complexation character of the supramolecular form of this dye, there is some discrepancy in respect to thioflavins $\mathrm{T}$ and $\mathrm{S}$, which, although differing essentially in structure and properties, are used interchangeably to stain amyloids (Le Vine 1999; Carrotta et al., 2001; Nielsen et al., 2001; Zhuang et al., 2001; Pavlov et al., 2002; Devlin et al., 2002). The planar, elongated components (Fig. 1 i) of thioflavin S, negatively charged at the ends, may overlap, producing symmetric dimers and then longer micellar structures, finally favoring complexation in the manner of Congo red. This explanation is supported by the observed high $\mathrm{R}$ value for this dye. In contrast, the polarity distribution of the thioflavin $\mathrm{T}$ molecule seems unsuited to self-assembling although its molecule is planar. Consequently, the yield of its complexation with proteins appeared also low. This seems consistent with the known direct dependence of this dye's fluorescence on growing amyloid fibrils, while it is poor or absent in the presence of individual molecules of amyloidogenic proteins. The standard quenching of fluorescence in solutions probably can be prevented here by immobilizing the dye molecules adsorbed to the highly ordered amyloid protein structure, even if the binding specificity is not necessarily of the Congo red type (Nakashima et al., 1995).

For optimal adhesion, complexation of supramolecular Congo red-related dye ligands to proteins requires a special ribbon-like organization and an extra adaptation to the protein receptor surface. Although the compact self-assembled form of the dye is required for adhesion to polypeptides, very high rigidity of the supramolecular ligand seems unsuitable, since the increasing micellar rigidity makes the adhering structures more difficult to adjust to each other.

The dyes were synthesized by Dr. Jan Boksa from the Institute of Pharmacology of the Polish Academy of Sciences (Kraków).

\section{R E F E R E N C E S}

Attwood TK, Lydon JE, Hall C, Tiddy GJT. (1990) The distinction between chromonic and amphiphilic lyotropic mesophases. Liquid Crystals.; 7: 657-68.

Awan T, Forloni G, Ragg E, Iussich S, Rossi G, Colombo L, Girola L, Massignan T, Bugiani O, Salmona M, Tagliavini F. (2001) Therapeutic approaches to prion diseases: In vitro studies with tetracycline compounds. In: $A l z-$ heimer's disease: advances in etiology, pathogenesis and therapeutics. Iqbal $\mathrm{K}$, 
Sisodia SS, Winblad B. eds, pp 809-20. John Wiley \& Sons Ltd.

Carrotta R, Bauer R, Waninge R, Rischel C. (2001) Conformational characterization of oligomeric intermediates and aggregates in $\beta$-lactoglobulin heat aggregation. Protein Sci.; 10: $1312-8$.

Carter DB, Chou K-C. (1998) A model for structure-dependent binding of Congo red to $\mathrm{Alz}$ heimer $\beta$-amyloid fibrils. Neurobiol Aging.; 19: $37-40$.

Caughey WS, Raymond LD, Horiuchi M, Caughey B. (1998) Inhibition of protease-resistant prion protein formation by porphyrins and phthalocyanines. Proc Natl Acad Sci U S A.; 95: 12117-22.

Chiti F, Webster P, Taddei N, Chiti F, Webster P, Taddei N, Clark A, Stefani M, Ramponi G, Dobson CM. (1999) Designing conditions for in vitro formation of amyloid protofilaments and fibrils. Proc Natl Acad Sci U S A.; 96: 3590-4.

Demaimay R, Harper J, Gordon H, Weaver D, Chesebro B, Caughey B. (1998) Structural aspects of Congo red as an inhibitor of protease-resistant prion protein formation. $J$ Neurochem.; 71: 2534-41.

Devlin GL, Chow MKM, Howlett GJ, Bottomley SP. (2002) Acid denaturation of $\alpha 1$-antitrypsin: characterization of a novel mechanism of serpin polymerization. $J \mathrm{Mol}$ Biol.; 324: 859-70.

Gazit E. (2002) A possible role for $\pi$-stacking in the self-assembly of amyloid fibrils. FASEB J.; 16: 77-83.

Glenner GG, Eanes ED, Page DL. (1972) The relation of the properties of Congo red-stained amyloid fibrils to the $\beta$-conformation. J Histochem Cytochem.; 20: 821-6.

Glenner GG, Eanes ED, Bladen HA, Linke RP, Termine JD. (1974) $\beta$-pleated sheet fibrils a comparison of native amyloid with synthetic protein fibrils. J Histochem Cytochem.; 22: 1141-58.

Howlett DR, Perry AE, Godfrey F, Swatton JE, Jennings KH, Spitzfaden C, Wadsworth H, Wood SJ, Markwell RE. (1999) Inhibition of fibril formation in $\beta$-amyloid peptide by a novel series of benzofurans. Biochem J.; 340: 283-9.

Howlett DR, George AR, Owen DE, Ward RV, Markwell RE. (1999) Common structural features determine the effectiveness of carvedilol, daunomycin and rolitetracycline as inhibitors of Alzheimer $\beta$-amyloid fibril formation. Biochem J.; 343: 419-23.

Janek K, Behlke J, Zipper J, Fabian H, Georgalis Y, Beyermann M, Bienert M, Krause E. (1999) Water-soluble $\beta$-sheet models which self-assemble into fibrillar structures. Biochemistry.; 38: 8246-52.

Kallberg Y, Gustafsson M, Persson B, Thyberg J, Johansson J. (2001) Prediction of amyloid fibril-forming proteins. $J$ Biol Chem.; 276: 12945-50.

Kaszuba J, Konieczny L, Piekarska B, Roterman I, Rybarska J. (1993) Bis-azo dyes interference with effector activation of antibodies. J Physiol Pharmacol.; 44: 233-42.

Khurana R, Uversky VN, Nielsen L, Fink AL. (2001) Is Congo red an amyloid-specific dye? J Biol Chem.; 276: 22715-21.

Kim J-S, Wall JS, Meyer J, Murphy C, Randolph TW, Manning MC, Solomon A, Carpenter JF. (2000) Thermodynamic modulation of light chain amyloid fibril formation. J Biol Chem.; 275: 1570-4.

Klunk WE, Debnath ML, Pettegrew JW. (1994) Development of small molecule probes for the $\beta$-amyloid protein of Alzheimer's disease. Neurobiol Aging.; 15: 691-8.

Kuner P, Bohrmann B, Tjernberg LO, Näslund J, Huber G, Celenk S, Grüninger-Leitch F, Richards JG, Jakob-Rotne R, Kemp JA, Nordstedt C. (2000) Controlling polymerization of $\beta$-amyloid and prion-derived peptides with synthetic small molecule ligands. $J$ Biol Chem.; 275: 1673-8.

Lansbury PT Jr. (1999) Evolution of amyloid: What normal protein folding may tell us about fibrillogenesis and disease. Proc Natl Acad Sci U S A.; 96: 3342-4. 
Le Vine III H. (1999) Quantification of $\beta$-sheet amyloid fibril structures with thioflavin T. Methods Enzymol.; 309: 274-84.

Li L, Darden TA, Bartolotti L, Kominos D, Pedersen LG. (1999) An atomic model for the pleated $\beta$-sheet structure of $\mathrm{A} \beta$ amyloid protofilaments. Biophys J.; 76: 2871-8.

Lin Y-M, Raffen R, Zhou Y, Cassidy CS, Flavin MT, Steven FJ. (2001) Amyloid fibril formation in microwell plates for screening of inhibitors. Amyloid.; 8: 182-93.

Lyon HO. (2002) Dye purity and dye standardization for biological staining. Biotech Histochem.; 77: 57-80.

Maeda N, Chen N, Tirrell M, Israelachvili JN. (2002) Adhesion and friction mechanisms of polymer-on-polymer surfaces. Science.; 297: 379-82.

Nakashima K, Fujimoto Y, Kido N. (1995) Fluorescence studies on the adsorption of octadecylrhodamine B onto a latex surface. Photochem Photobiol.; 62: 674-9.

Neri A. (1929) Monosulfonic derivatives of 2-N-phenyl-1,2-naphtho-1,2,3-triazole. Gazz Chim Ital.; 59: 384-91.

Nielsen L, Khurana R, Coats A. (2001) Effect of environmental factors on the kinetics of insulin fibril formation: elucidation of the molecular mechanism. Biochemistry.; 40: 6036-46.

Novelli A, Ruiz C. (1928) New substantive dyes derived from 2,7-diaminofluorene. Ann Asocn Quim Argent.; 16: 56-64.

Pavlov NA, Cherny DI, Heim G, Jovin TM, Subramaniam V. (2002) Amyloid fibrils from the mammalian protein prothymosin $\alpha$. FEBS Lett.; 517: 37-40.

Piekarska B, Roterman I, Rybarska J, Konieczny L, Kaszuba J. (1994) The melting of native domain structure in effector activation of IgG studied by using Congo red as a specific probe. $J$ Physiol Pharmacol.; 45: $147-62$

Piekarska B, Skowronek M, Rybarska J, Stopa B, Roterman I, Konieczny L. (1996) Congo red-stabilized intermediates in the $\lambda$ light chain transition from native to molten state. Biochimie.; 78: 183-9.

Piekarska B, Rybarska J, Stopa B, Zemanek G, Król M, Konieczny L. (1999) Supramolecularity creates nonstandard protein ligands. Acta Biochim Polon.; 46: 841-51.

Piekarska B, Konieczny L, Rybarska J, Stopa B, Zemanek G, Szneler E, Król M, Nowak M, Roterman I. (2001) Heat-induced formation of a specific binding site for self-assembled Congo red in the $\mathrm{V}$ domain of immunoglobulin L chain $\lambda$. Biopolymers.; 59: 446-56.

Pollack SJ, Sadler IIJ, Hawtin SR, Tailor VJ, Shearman MS. (1995) Sulfonated dyes attenuate the toxic effects of $\beta$-amyloid in a structure-specific fashion. Neurosci Lett.; 197: 211-4.

Priola SA, Caughey B, Caughey WS. (1999) Novel therapeutic uses for porphyrins and phthalocyanines in the transmissible spongiform encephalopathies. Curr Opin Microbiol.; 2: 563-6.

Raffen R, Dieckman LJ, Szpunar M, Wunschl C, Pokkuluri PR, Dave P, Stevens PW, Cai X, Schiffer M, Stevens FJ. (1999) Physicochemical consequences of amino acid variations that contribute to fibril formation by immunoglobulin light chains. Protein Sci.; 8: 509-17.

Ramirez-Alvarado M, Merkel JS, Regan L. (2000) A systematic exploration of the influence of the protein stability on amyloid fibril formation in vitro. Proc Natl Acad Sci U S A.; 97: 8979-84.

Randolph TW, Seefeldt M, Carpenter JF. (2002) High hydrostatic pressure as a tool to study protein aggregation and amyloidosis. Biochim Biophys Acta.; 1595: 224-34.

Reixach N, Crooks E, Ostresh JM, Houghten RA, Blondelle SE. (2000) Inhibition of $\beta$-amyloid-induced neurotoxicity by imidazopyridoindoles derived from a synthetic combination library. J Struct Biol.; 130: 247-58.

Rollet A, Bacher W. (1940) Azo dyes IV. Monatsh.; 73: 20-4.

Rostagno A, Vidal R, Kaplan B, Chuba J, Kumar A, Elliott JI, Frangione B, Gallo G, 
Ghiso J. (1999) pH-dependent fibrillogenesis of a V $[\kappa]$ III Bence Jones protein. $B r J$ Haematol.; 107: 835-43.

Roterman I, No K-T, Piekarska B, Kaszuba J, Pawlicki R, Rybarska J, Konieczny L. (1993) Bis azo dyes - studies on the mechanism of complex formation with IgG modulated by heating or antigen binding. $J$ Physiol Pharmacol.; 44: 213-32.

Roterman I, Rybarska J, Konieczny L, Skowronek M, Stopa B, Piekarska B. (1998) Congo red bound to $\alpha$-1-proteinase inhibitor as a model of supramolecular ligand and protein complex. Comput Chem.; 22: 61-70.

Roterman I, Król M, Nowak M, Konieczny L, Rybarska J, Stopa B, Piekarska B, Zemanek G. (2001) Why Congo red binding is specific for amyloid proteins - model studies and a computer analysis approach. Med Sci Monit.; 7: 771-84.

Rudyk H, Vasiljevic S, Hennion RM, Birkett CR, Hope J, Gilbert IH. (2000) Screening Congo red and its analogues for their ability to prevent the formation of PrP-res in scrapie-infected cells. J Gen Virol.; 81: 1155-64.

Rybarska J, Piekarska B, Konieczny L, Roterman I. (1988) The formation of soluble heat IgG aggregates for immunological studies. Arch Immunol Ther Exp (Warsz).; 36: 609-22.

Rybarska J, Konieczny L, Roterman I, Piekarska B. (1991) The effect of azo dyes on the formation of immune complexes. Arch Immunol Ther Exp (Warsz).; 39: 317-27.

Rybarska J, Konieczny L, Piekarska B, Stopa B, Roterman I. (1995) The detection of acute phase serum protein complexes and immune complexes by Congo red binding. $J$ Physiol Pharmacol.; 46: 221-31.

Rybarska J, Piekarska B, Stopa B, Zemanek G, Konieczny L, Nowak M, Król M, Roterman I, Szymczakiewicz-Multanowska A. (2001) Evidence that supramolecular Congo red is the sole ligation form of this dye for $\mathrm{L}$ chain $\lambda$ derived amyloid proteins. Folia Histochem Cytobiol.; 39: 307-14.
Serpel LC, Sunde M, Blake CCF. (1997) The molecular basis of amyloidosis. Cell Mol Life Sci.; 53: 871-87.

Sinha N, Tsai C-J, Nussinov R. (2001) A proposed structural model for amyloid fibril elongation: domain swapping forms an interdigitating $\beta$-structure polymer. Protein Eng.; 14: 93-103.

Sipe JD. (1992) Amyloidosis. Annu Rev Biochem.; 61: 947-75.

Skowronek M, Stopa B, Konieczny L, Rybarska J, Piekarska B, Szneler E, Bakalarski G, Roterman I. (1998) Self-assembly of Congo red - a theoretical and experimental approach to identify its supramolecular organization in water and salt solutions. Biopolymers.; 46: 267-81.

Skowronek M, Roterman I, Konieczny L, Stopa B, Rybarska J, Piekarska B. (2000) Why do Congo red, Evans blue and Trypan blue differ in their complexation properties? $J$ Computat Chem.; 21: 656-67.

Stopa B, Górny M, Konieczny L, Piekarska B, Rybarska J, Skowronek M, Roterman I. (1998) Supramolecular ligands: Monomer structure and protein ligation capability. Biochimie.; 80: 963-8.

Sunde M, Blake C. (1997) The structure of amyloid fibrils by electron microscopy and X-ray diffraction. Adv Protein Chem.; 50: 123-59.

Sunde M, Blake CCF. (1998) From the globular to the fibrous state: protein structure and structural conversion in amyloid formation. Quat Rev Biophys.; 31: 1-39.

Turnell WG, Finch JT. (1992) Binding of the dye Congo red to the amyloid protein pig insulin reveals a novel homology amongst amyloid-forming peptide sequences. $J$ Mol Biol.; 227: 1205-23.

Wall J, Schell M, Murphy C, Hrncic C, Stevens FJ, Solomon A. (1999) Thermodynamic instability of human $\lambda 6$ light chains: Correlation with fibrillogenicity. Biochemistry.; 38: 14101-8.

Wasilewskaya AC, Generalova EW, Sonin AC. (1989) Chromonic mesophases. Usp Khim.; 58: 1574-96. 
West MW, Wang W, Patterson J, Mancias JD, Beasley JR, Hecht MH. (1999) De novo amyloid proteins from designed combinatorial libraries. Proc Natl Acad Sci U S A.; 96: 11211-6.

Westermark GT, Johnson KH, Westermark P. (1999) Staining methods for identification of amyloid in tissue. Methods Enzymol.; 309: $3-25$.

Wetzel R. (1997) Domain stability in immunoglobulin light chain deposition disorders. $A d v$ Protein Chem.; 50: 183-242.

Zemanek G, Konieczny L, Piekarska B, Rybarska J, Stopa B, Spólnik P, Urbanowicz
B, Nowak M, Król M, Roterman I. (2002) Egg yolk platelet proteins from Xenopus laevis are amyloidogenic. Folia Histochem Cytobiol.; 40: 311-8.

Zhen W, Han H, Anguiano M, Lemere CA, Cho C-G, Lansbury PT Jr. (1999) Synthesis and amyloid binding properties of rhenium complexes: preliminary progress toward a reagent for SPECT imaging of Alzheimer's disease brain. J Med Chem.; 42: 2805-15.

Zhuang Z-P, Kung M-P, Hou C. (2001) Radioiodinated styrylbenzenes and thioflavins as probes for amyloid aggregates. J Med Chem.; 44: 1905-14. 